\section{Tradition reimagined}

Are you looking to move on from traditional film imaging but are not comfortable with a complete transition to digital? The CS 7200 imaging plate system from Carestream Dental is the innovation for you.

Bridging the gap between film and digital, the CS 7200 produces images with a true resolution of $17 \mathrm{Ip} / \mathrm{mm}$ for superior clarity and accuracy. The wide exposure range, powerful image processing and simple workflow facilitate the capture of ideal diagnostic images for a smooth workflow and quality patient service.

For more information, call 0800169 9692 or visit www.carestreamdental.co.uk.

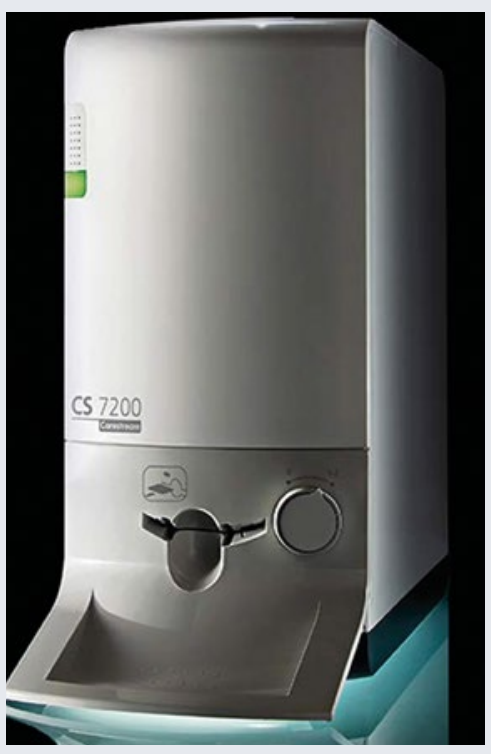

\section{Comprehensive occlusion, clinical records and bite splints course}

A unique and comprehensive four day hands-on course to give delegates a thorough and clinically relevant understanding of occlusion is taking place on 7 to 10 May 2019, organised by Mizrahi Dental Teaching.

The course will be given by Dr Basil Mizrahi and Dr Jurgita Sybaite.

Rather than focus on specific philosophies and concepts, it will start off with the basic nuts and bolts such as occlusal contacts and tooth morphology and build up to more complex aspects such as mandibular movement and occlusal adjustment.

Practical and exercises will make use of giant tooth models and drawings. To complete the topic, delegates will be taught about occlusal splints and their therapeutic principles.

Differences and use in clinical practice will be discussed in detail. Each delegate will have the opportunity to fit and adjust a full upper bite splint. Upon completion, ing on practical application of occlusal principles.

The course runs from 7 to 10 May 2019 in central London.

For more information on this and other upcoming courses, contact Mizrahi Dental Teaching by email at info@mizrahi-dental-teaching.co.uk, visit www.mizrahi-dental-teaching.co.uk or call 02033942984. delegates will develop a clear understand-

\section{Care every step of the way}

Root canal treatments can be daunting, but if dental professionals refer anxious patients to EndoCare - one of the UK's most trusted specialist endodontist practices - it can put their minds at ease.

Not only are its team of endo-experts prepared for even the most complex of cases, EndoCare can also ensure that it provides patients with pain-free treatment.

After EndoCare has helped patients, they will be returned to dental practitioners' care with full information passed on about the exact treatment given, the

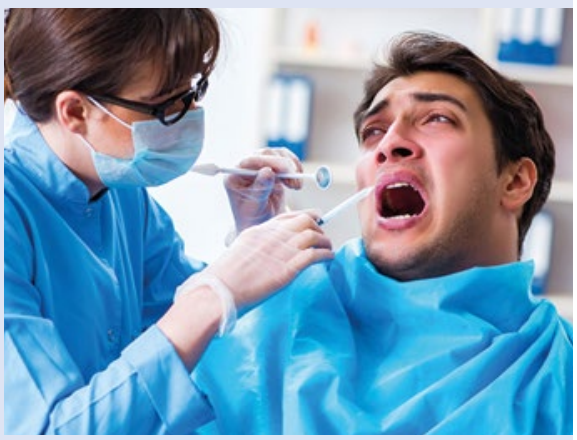

relevant aftercare and suggested steps for the future - care every step of the way.

For more information, call 0207224 0999 or visit www.endocare.co.uk.

\section{Root canal made easier with} expanded endodontic hand file

\section{range}

UnoDent, Dental Directory's own-brand, has launched one of the UK's largest ranges of endodontic hand files to facilitate greater precision and optimise disinfection for root canal treatments.

The newly extended range features more than 380 instruments including K-files, reamers, pluggers, spreaders, barbed broaches, Peeso reamers and Gates Glidden drills.

Endodontic files and reamers are surgical instruments used by dentists performing root canal treatment. They are used to clean and shape the root canal removing dead, damaged or infected material to the opening at the apex of the tooth root. Using the files provides a shape that is receptive to subs equent filling.

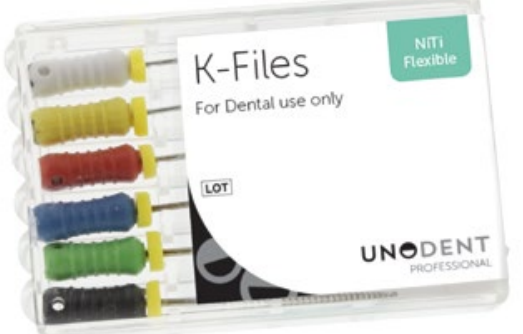

All the instruments are available in stainless steel and NiTi options, making them durable and flexible. NiTi files come pre-sterile and ready to use and all files can be sterilised to 150 degrees.

In addition to extending the range, UnoDent has also upgraded its hand files to offer clinicians greater quality and better results.

Gary Bond, Restoratives and Endodontic Category Manager for Dental Directory, said: 'Endodontics is a specialist area that requires specialist instruments to provide the best possible results for the patient.

'The launch of our new endodontic hand file range offers dentists more choice of instrument size and material combining quality re-usable products at competitive prices. It also demonstrates what's going on behind the scenes at UnoDent as we work to build a full and comprehensive endodontic range.'

The new endodontic range of UnoDent hand files are now available exclusively through Dental Directory.

For more information, visit www. dental-directory.co.uk. 